\title{
3D morphometric analysis of ascending aorta as an adjunctive tool to predict type $A$ acute aortic dissection
}

\author{
Wael Saade $^{1} \wedge$, Mattia Vinciguerra ${ }^{1}$, Silvia Romiti ${ }^{1}$, Francesco Macrina ${ }^{1}$, Giacomo Fratii ${ }^{2,3}$, Fabio Miraldi ${ }^{1}$, \\ Ernesto Greco ${ }^{1}$
}

${ }^{1}$ Department of Clinical, Internal Medicine, Anaesthesiology and Cardiovascular Sciences, Sapienza University of Rome, Rome, Italy; ${ }^{2}$ Department of Medico-Surgical Sciences and Biotechnologies, "Sapienza" University of Rome, Rome, Italy; ${ }^{3}$ IRCCS NEUROMED, Pozzilli, Italy

Contributions: (I) Conception and design: W Saade, E Greco; (II) Provision of study materials or patients: W Saade; (III) Collection and assembly of data: W Saade, M Vinciguerra, S Romiti; (IV) Data analysis and interpretation: W Saade, F Macrina, G Frati, F Miraldi, E Greco; (V) Manuscript writing: All authors; (VI) Final approval of manuscript: All authors.

Correspondence to: Wael Saade, MD. Department of Clinical, Internal Medicine, Anaesthesiology and Cardiovascular Sciences, Sapienza University of Rome, Rome, Italy. Email: Wael.saade@uniroma1.it.

Background: Acute type A aortic dissection (AAAD) is a pathological process that implicates the ascending aorta and represents a surgical emergency burdened by high mortality if not promptly treated in the first hours of onset. Despite best efforts, the annual incidence rates of aortic dissection has remained stable over the past decades. We measured aortic dimensions (aortic diameters, area, length and volume) using 3D multiplanar reconstruction imaging with the purpose of refining the risk- morphology for AAAD.

Methods: Computerized tomography angiography studies of three groups were compared retrospectively: patients affected by AAAD (AAAD group; $n=71$ ), patients affected by aortic aneurysm and subsequently subjected to ascending aorta replacement (Aneurysm, n=77) and a healthy aorta's group (Control, $\mathrm{n}=75$ ).

Results: Mean diameters of AAAD $(4.9 \mathrm{~cm})$ and Aneurysm $(5.1 \mathrm{~cm})$ aortas were significantly larger than those of the control group $(3.4 \mathrm{~cm})$. In AAAD patients, an ascending aorta diameter greater than $5.5 \mathrm{~cm}$ was observed in $18 \%$ of patients. Multiple comparisons showed statistically significant differences among mean of the ratio of aortic root area to height between the three groups $(\mathrm{P}<0.001)$. In frontal and sagittal planes, the length of the ascending aorta was significantly greater in patients affected by aortic pathology (AAAD and aneurysm) than in the control group $(\mathrm{P}<0.001)$. Significant differences were confirmed when indexing the aortic length to patient's height and BSA, and the aortic volume to patient's BSA.

Conclusions: Maximum transverse diameter, considered separately, is not the best predictor of aortic dissection. In our opinion, the introduction into clinical practice of measurements of the area, length, and volume of the aorta, as absolute or indexed values, could improve the selection of patients who would benefit from preventive surgical aortic replacement.

Keywords: Acute type A aortic dissection (AAAD); aortic diameter; aortic dimensions; aortic length; aortic volume

Submitted Jan 19, 2021. Accepted for publication Apr 09, 2021.

doi: $10.21037 /$ jtd-21-119

View this article at: http://dx.doi.org/10.21037/jtd-21-119

$\wedge$ ORCID: 0000-0001-6617-6103. 


\section{Introduction}

Acute type A aortic dissection (AAAD) is a pathological process that affects the ascending aorta and represents a surgical emergency burdened by high mortality if not promptly treated in the first hours of onset. Even in case of favorable outcome because of a successful surgery or an evolution into a chronic phase, the patient remains at risk of major complications. In fact, the progression of the pathological process and the persistence of false lumen at the level of the distal aorta (1) is the most important determinant of long-term survival. In addition, the duration of hospitalization, health costs, reduced quality of life and, often, the need for re-operations are all factors that affect long-term survival of most patients.

Recent publications have focused on identifying new morphological predictors or morphological risk factors with the purpose to improve screening and prevention of AAAD since the simple reduction of the maximum aortic diameter cut-off value would not necessarily imply a net benefit in terms of mortality (2-6).

In this retrospective cohort study, we identified three groups of patients in order to assess and to compare the morphology of dissected, aneurysmatic and healthy aortas based on an analysis of the computed tomography angiography studies.

We present the following article in accordance with the STROBE reporting checklist (available at http://dx.doi. org/10.21037/jtd-21-119).

\section{Methods}

\section{Patients' groups and clinical data}

The study was conducted in accordance with the Declaration of Helsinki (as revised in 2013). The National Code on Clinical Trials has declared that ethics approval is not necessary for real retrospective studies. All our patients sign a consent for medical/surgical treatment, privacy terms, future studies and participate in research. This study represents a retrospective observational analysis of three groups of patients. We identified all patients admitted to our center diagnosed with AAAD from December 2005 to March 2020 (302 patients). The exclusion criteria were: (I) unavailability or inadequacy of CTA studies; (II) chronic, retrograde, traumatic, iatrogenic or postoperative AAAD; (III) lack of anthropometric data (weight and height); (IV) connective tissue disorders; (V) patients diagnosed with intramural hematoma or penetrating aortic ulcer. A total of 71 patients with AAAD formed a subgroup in which radiological studies (CTA) were available and adequate for the purpose of this study. In the second group we identified patients affected by ascending aortic aneurysm and who subsequently underwent cardiac surgery (234 patients) with the availability of CTA scan images $(n=77)$ and control patients suffering from heart disease and undergoing cardiac surgery not involving the thoracic aorta $(n=75)$. The following demographical and clinical parameters were collected: age at admission, gender, weight, height and diagnosis of arterial hypertension, atherosclerosis (coronary or other arterial districts), type 2 diabetes mellitus, bicuspid aortic valve, bovine aortic arch. Hypertension was diagnosed on the basis of the presence of one or more antihypertensive drugs in the chronic medications: central and peripheral vasodilators and calcium channel blockers, angiotensin converting enzyme inhibitors, angiotensin II receptor antagonists, $\beta$-blockers but not diuretics.

\section{Image analysis}

CTA studies were analyzed and processed using the Horos ${ }^{\mathrm{TM}}$ superscripted PACS-Viewer (Horos Project, Maryland, United States). To visualize the aorta, multiplanar reconstructions were used. All measurements were performed manually by applying the software's graphical measurement tools (Figure 1). For reporting the measurement of the aortic diameters, international guidelines were followed $(7,8)$. Diameters were measured using the inner edge to inner edge technique. In the axial planes, the diameters of the ascending and descending sections of the thoracic aorta were measured at the height of the bifurcation of the pulmonary artery (PA). In the transverse planes, we measured the aortic root diameter and area. In order to avoid any overestimation of such measures, the "double-oblique technique" was used (9). The length of the ascending aorta was measured along the central line of the aorta, in frontal and sagittal planes, as the distance between the aortic valve plane and the emergence of the brachiocephalic trunk. Although the ascending aorta is traditionally defined as the segment running from the sinotubular junction to the anonymous artery, in AAAD and ascending aortic aneurysms, the sinotubular junction is often lost or difficult to identify, hence the choice of using the aortic annulus as a proximal reference point provides more reproducible measurements. On the frontal plane, the planes at the level of the "virtual basal ring" and the origin of the brachiocephalic trunk 
A

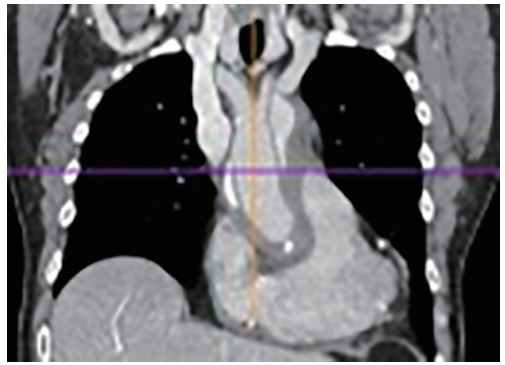

B

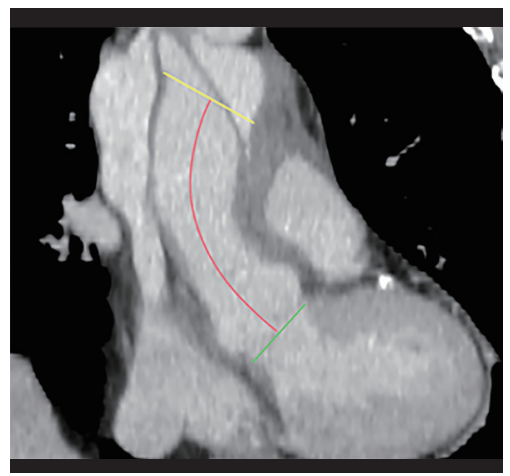

C

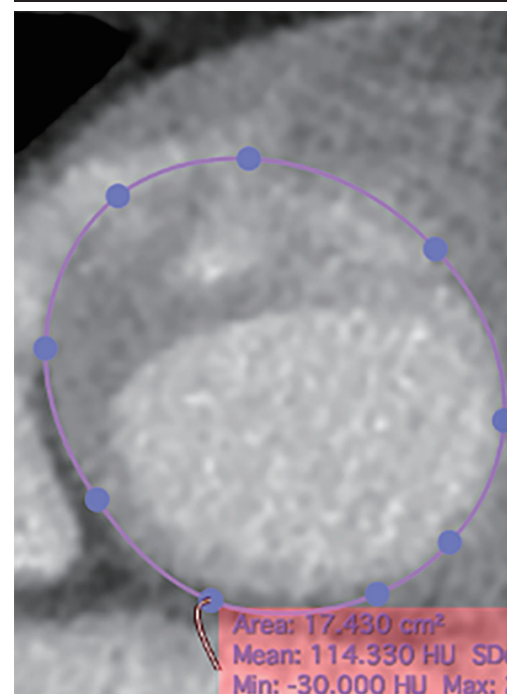

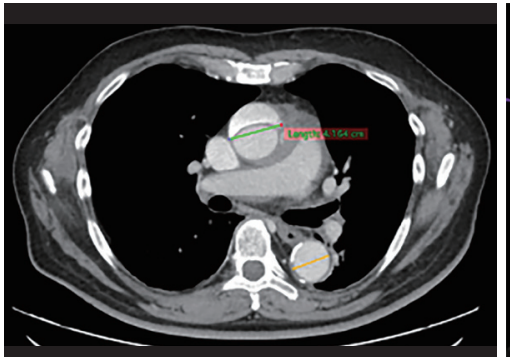

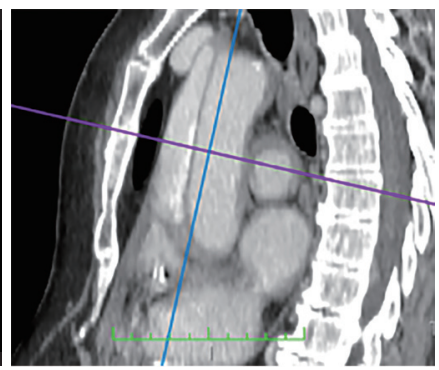

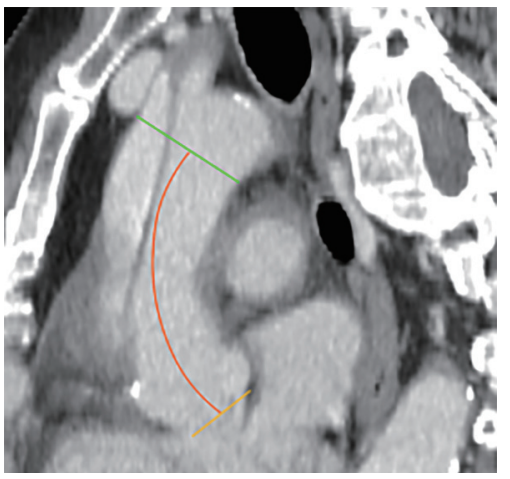

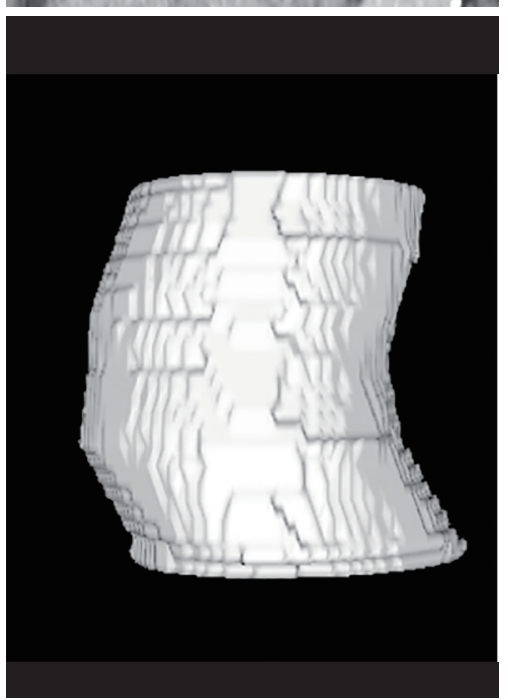

Figure 1 Measurements of aortic diameters, length, area and volume. (A) Diameter of the ascending and the descending aorta at the height of the PA, double-oblique technique. (B) Ascending aorta length in frontal plane and sagittal plane: Distance between the virtual basal ring and the BCT at the central line. (C) Aortic area defining "ROI"s and ascending aorta volume rendering.

were marked; with the use of these landmarks, the length of the ascending aorta was measured using the graphical measurement tools. An identical approach was used in the sagittal plane. Aortic volume was calculated using the tool provided by the software (Figure 1). In particular, the contours of the ascending aorta were manually selected, thus tracing the "Region Of interest" ROIs, on various sections following the axial axis from the plane passing just above the coronary ostia to the emergence of the brachiocephalic trunk. When it was necessary, the contours were manually corrected. Subsequently, through the automatic tracking of ROIs along the aorta (voxel of the same enhancement), with the use of an algorithm provided by the software, the segmentation volume was automatically calculated.

\section{Statistical analysis}

SSPS (SSPS 20.0, IBM Corp., Armonk, NY, USA) and 
Table 1 Demographic and clinical variables in the study groups

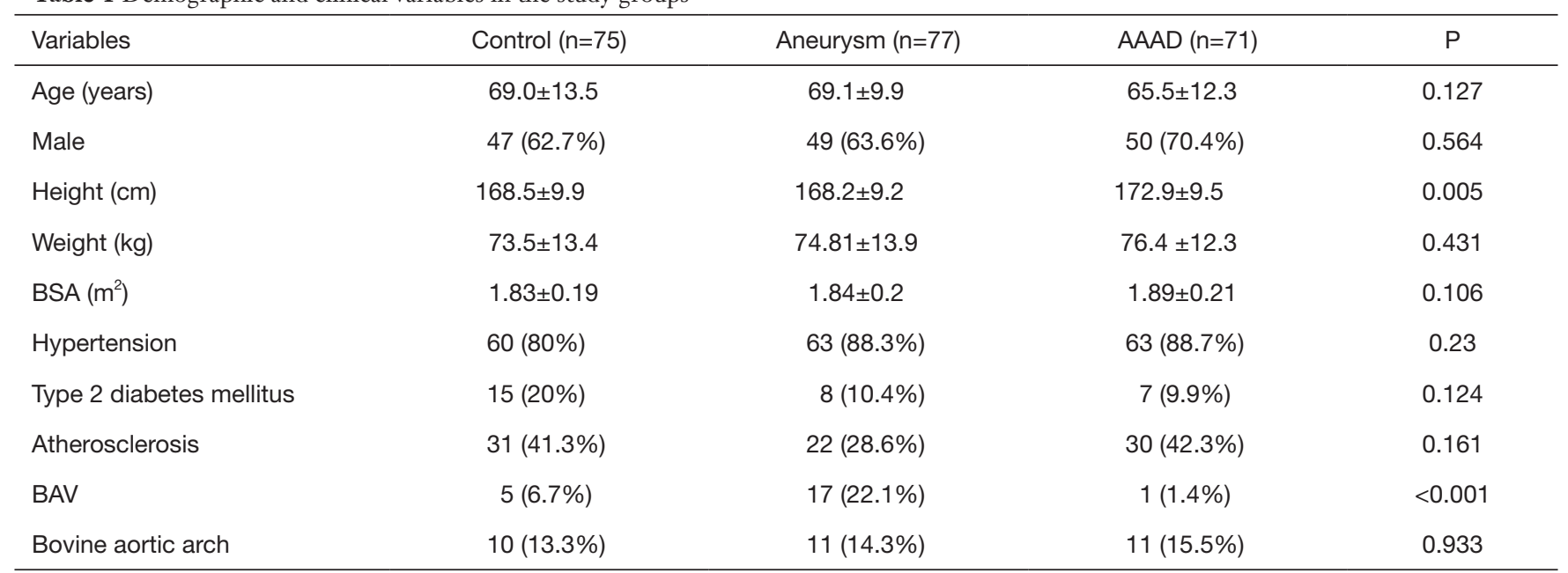

BAV, bicuspid aortic valve; BSA, body surface area; AAAD, acute type A aortic dissection.

Table 2 Cardiopathies and percentages of the control group

\begin{tabular}{lc}
\hline Cardiopathy & $\mathrm{N}(\%)$ \\
\hline Severe aortic stenosis & $34(45.3)$ \\
Ischemic heart disease & $20(26.6)$ \\
Mitral regurgitation & $11(14.6)$ \\
Aortic regurgitation & $10(13.3)$ \\
Bacterial endocarditis & $8(10.6)$ \\
Mitral stenosis & $1(1.3)$ \\
Renal tumors with IVC thrombosis & $1(1.3)$ \\
Pericardial effusion & $1(1.3)$ \\
Thoracic trauma & $1(1.3)$ \\
Abnormal origin of the right coronary artery & $1(1.3)$ \\
\hline
\end{tabular}

IVC, inferior vena cava.

Excel (MS Excel 2010, Microsoft, Redmond, WA, USA) were used for all data analysis and presentation. Continuous quantitative variables are described as the mean \pm standard deviation and presented with box-and-whiskers plots. Categorical data are described as percentages. To describe the correlation between the continuous variables, we used the Pearson coefficient and the Independent Samples $t$-test for categorical variables. For comparing groups, the analysis of variance (ANOVA) was first carried out using the Levene test to verify the homogeneity of the variables within the groups. Subsequently, a robust Welch and Brown-Forsythe test was used in the case of significance of the Levene test and the classic ANOVA test in the opposite case. Multiple comparisons were performed by Bonferroni $t$-test in the case of the Anova test and Tamhane test to evaluate the results of the Welch and Brown-Forsythe test. All reported $\mathrm{P}$ values are 2 -sided and $\mathrm{P}$ values $\leq 0.05$ were considered indicative of statistical significance.

\section{Results}

Demographic and clinical data are presented in Table 1. The data show a correspondence between the groups in terms of age, gender, weight and BSA. Significantly major height was observed in patients with AAAD compared with the aneurysms and controls group. The mean age \pm STD at presentation was $69.0 \pm 13.5$ years in the control group, $69.1 \pm 9.9$ years in the aneurysm group, and $65.5 \pm 12.3$ years in patients with AAAD.

The homogeneity among groups was also observed for the diagnosis of arterial hypertension, diabetes mellitus, atherosclerosis and the presence of the anatomical variant of the bovine aortic arch. In the ascending aortic aneurysm, the prevalence of bicuspid aortic valve was significantly higher (17 patients, 22.1\%) than in the control group (5 patients, $6.7 \%)$ and AAAD (1 patient, 1.4\%) $(\mathrm{P}<0.001)$.

The heart diseases for which control group patients were referred to our center are presented in Table 2. The most frequently observed diagnosis in the control group was severe aortic stenosis, present in $45.3 \%$ of cases, followed by ischemic heart disease $(26.6 \%)$ and mitral valve regurgitation (14.6\%). 


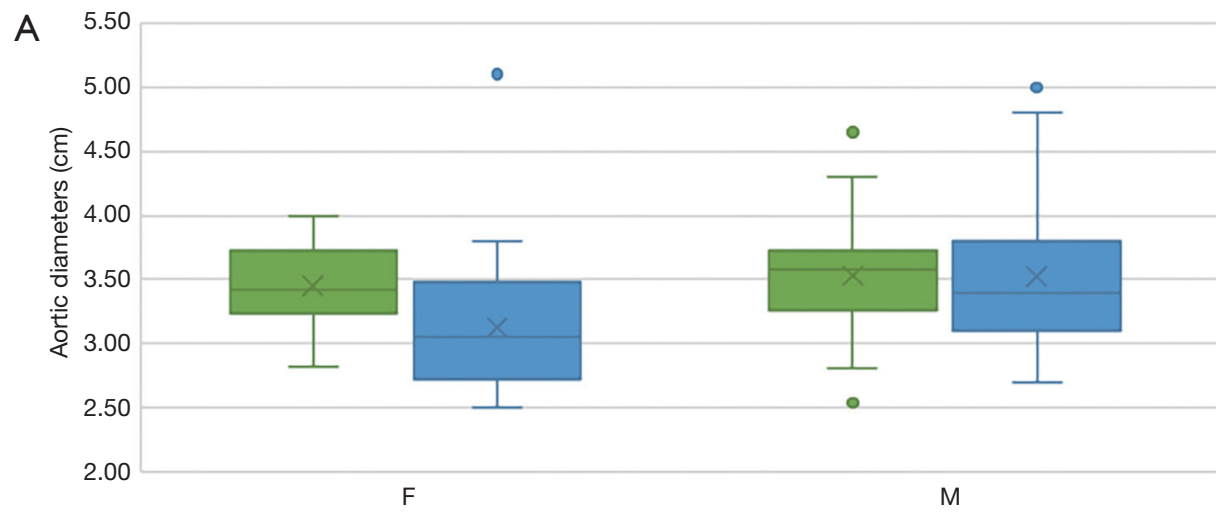

Ascending aorta

Aortic root
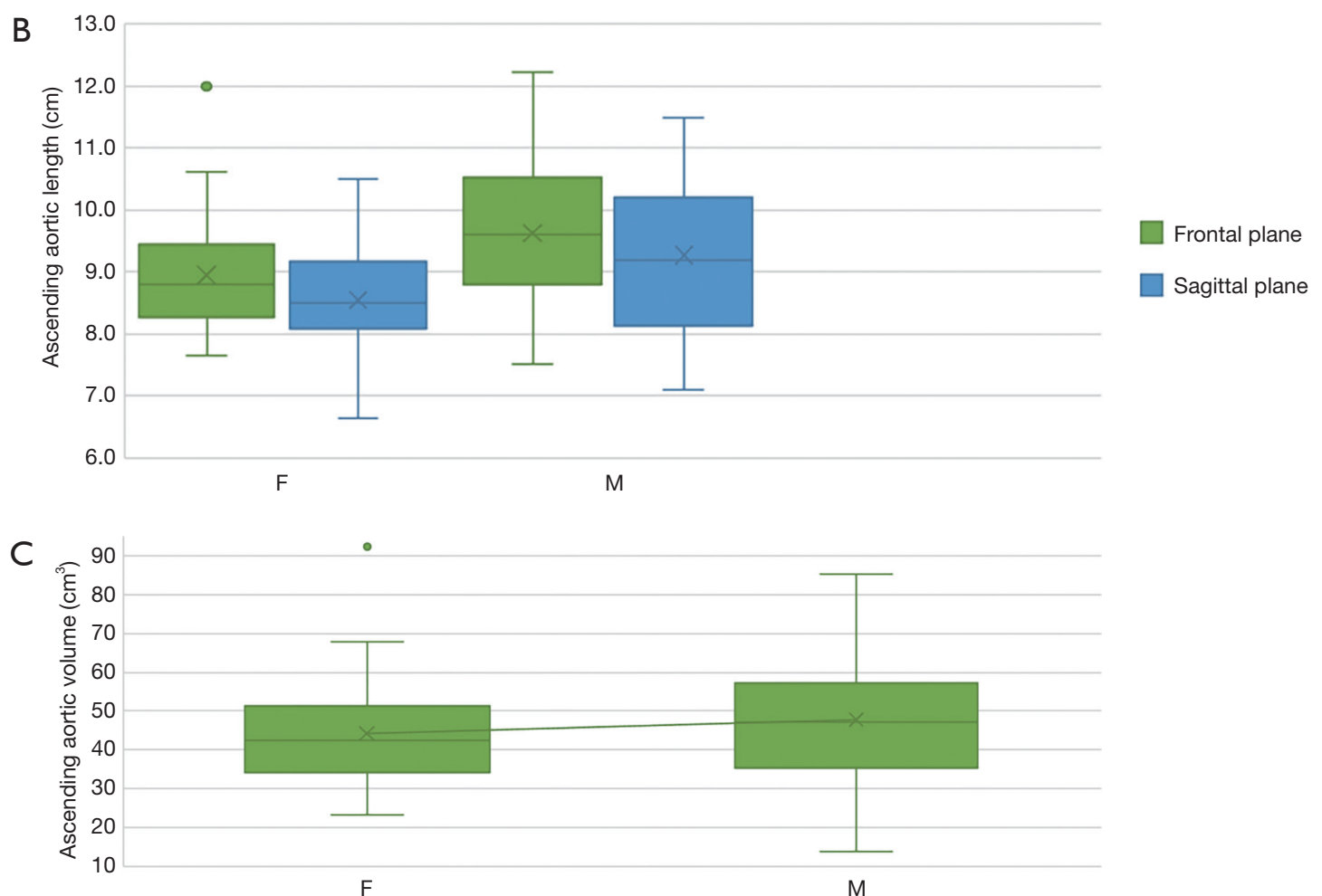

Figure 2 Box-and-whiskers plots presenting control group results. (A) Aortic diameters (cm) by gender: greater aortic diameters of aortic root were observed in males, (B) ascending aorta length $(\mathrm{cm})$ in both, frontal and sagittal, planes by gender: in both planes, ascending aorta was longer in males. (C) Ascending aorta volume $\left(\mathrm{cm}^{3}\right)$ by gender: ascending aorta volume was significantly higher in males in the control group.

\section{Control group analysis}

The diameters of aortic root (Figure $2 A$ ), ascending aortic length (Figure $2 B$ ), in both frontal and sagittal planes, and ascending aorta volume (Figure $2 C$ ) were significantly higher in males in the control group.

The length of the ascending aorta, in frontal and sagittal planes, showed a moderate correlation with the BSA
(Figure 3) $(\mathrm{r}=0.3, \mathrm{P}<0.005$ in both planes) and with the patient's height (Figure 3$)(\mathrm{r}=0.34$ in the frontal plane and 0.35 in the sagittal plane, $\mathrm{P}<0.002)$. No significant correlation with age was found (Figure 3). The volume of the ascending aorta showed a moderate correlation with age $(\mathrm{r}=0.3, \mathrm{P}<0.005)$ (Figure 3$)$ in the absence of correlation with BSA and height. 
A

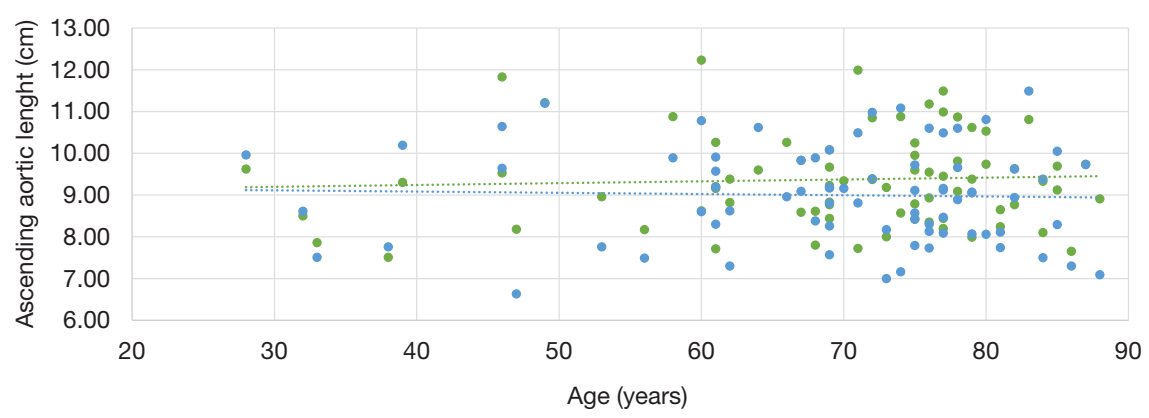

- Frontal plane - Sagittal plane …..... Frontal plane _........ Sagittal plane

B

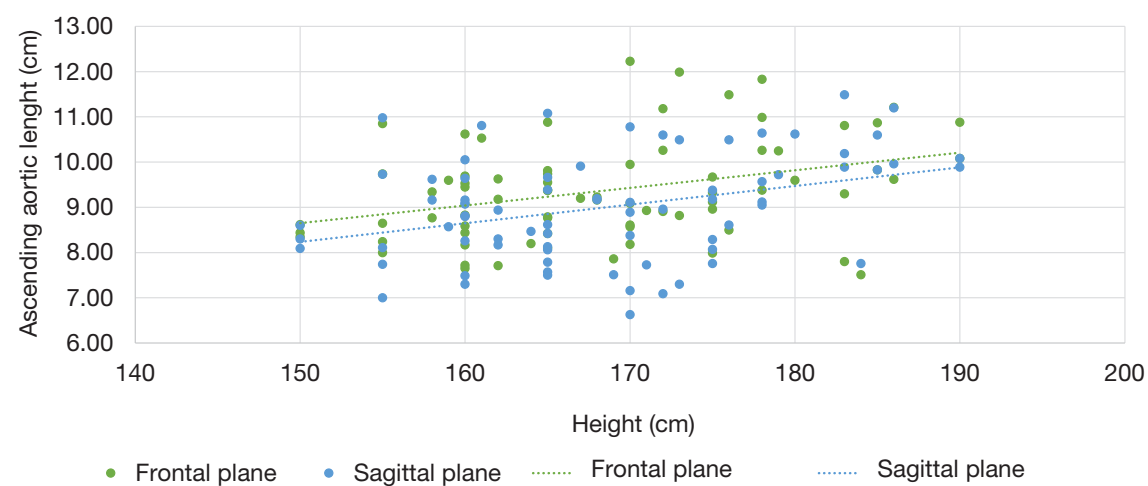

$C$

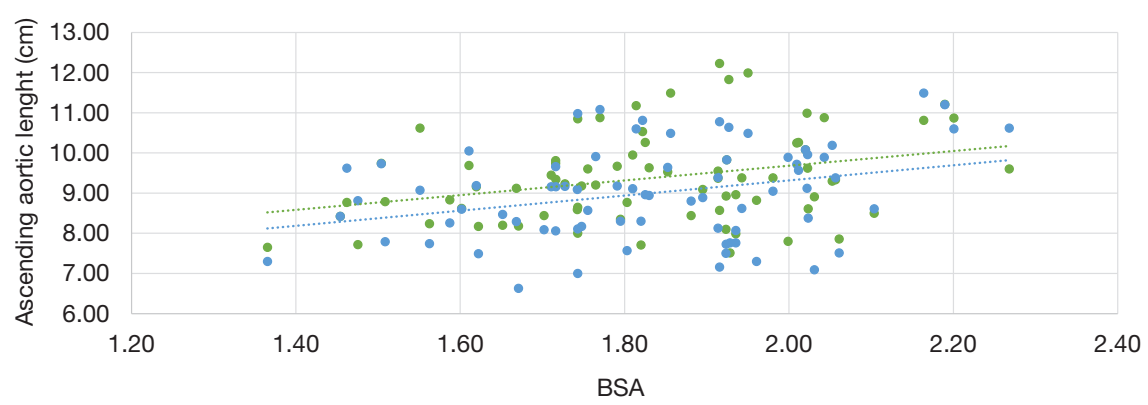

- Frontal plane - Sagittal plane …..... Frontal plane $\quad$......... Sagittal plane

$\mathrm{D}$

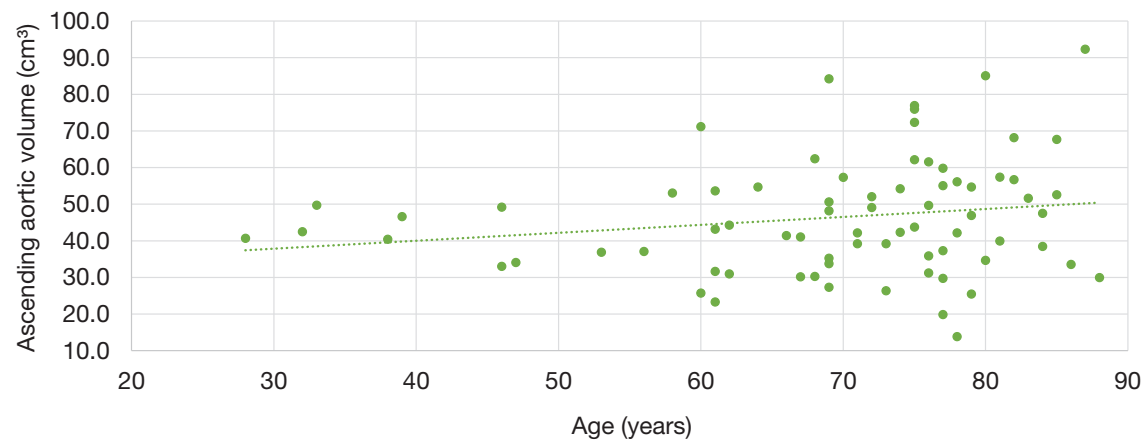

Figure 3 Scatter plots of age (A,D), height (B) and BSA (C) and the selected aortic dimensions.
This scatterplot shows no correlation between ascending aortic length in both plans and age in the control group.

This scatterplot shows a positive, linear, moderately strong correlation between ascending aortic length in both plans and patients' height in the control group.

This scatterplot shows a positive, linear, moderately strong correlation between ascending aortic length in both plans and patients' BSA in the control group.
This scatterplot shows a positive, linear, moderately strong correlation between ascending aortic volume and patients' age in the control group. 
Table 3 Aortic dimensions

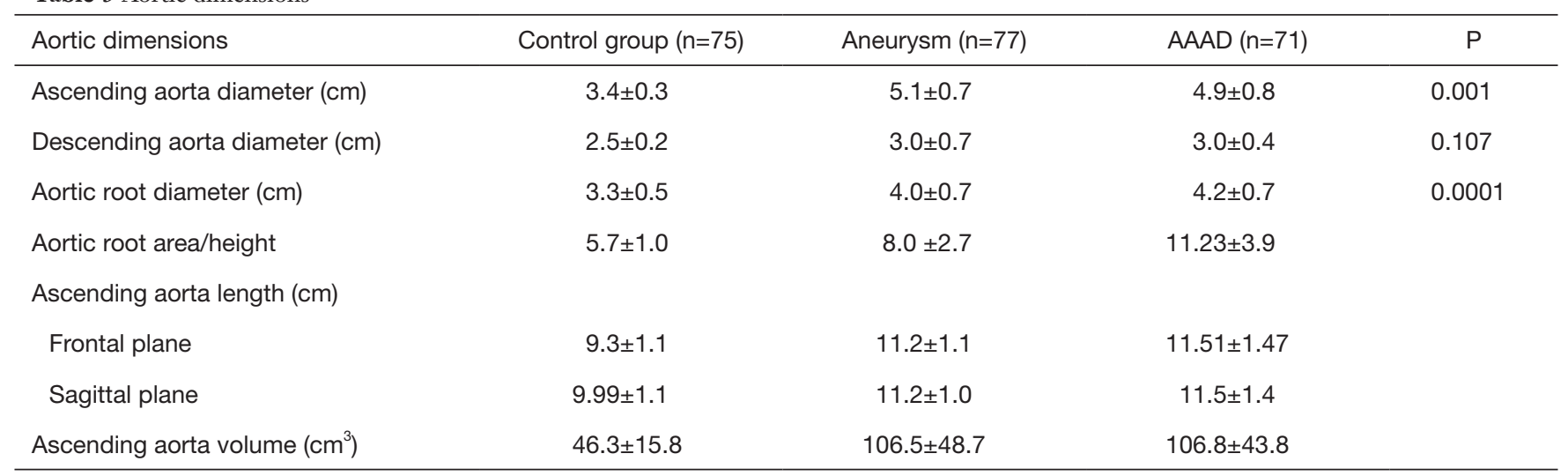

AAAD, acute type A aortic dissection.

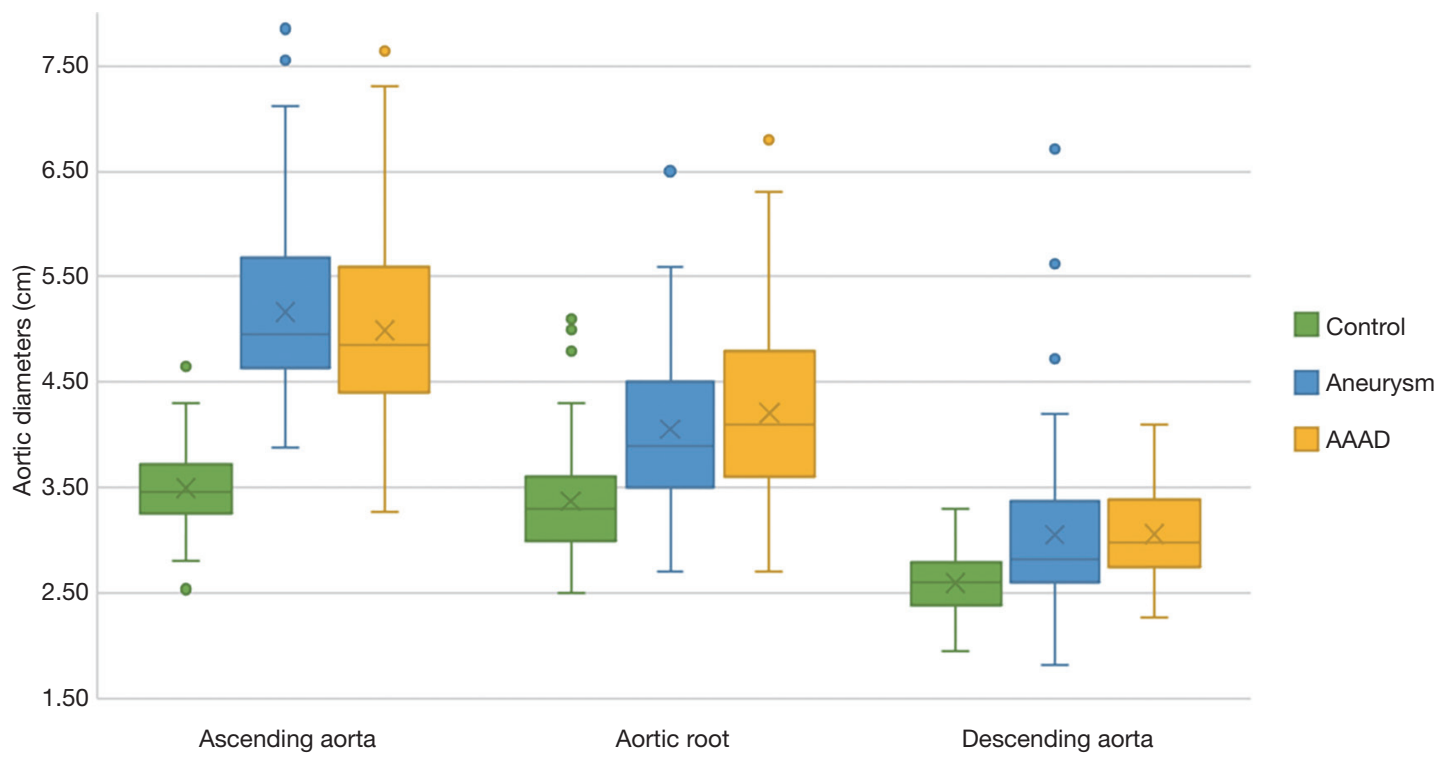

Figure 4 Box-and-whiskers plots presenting aortic diameters in the AAAD, Aneurysm and control groups. AAAD, acute type A aortic dissection.

\section{Aortic diameters}

The mean diameter of the ascending aorta at the bifurcation of the PA (Table 3) in the control group was $3.4 \pm 0.3 \mathrm{~cm}$. The maximum value found was $4.65 \mathrm{~cm}$ and the rest of the patients had a diameter of less than $4.3 \mathrm{~cm}$. In the aneurysm group, the mean diameter of the ascending aorta was $5.1 \pm 0.7 \mathrm{~cm}$. Moreover, 23 of 77 patients (29\%) had a diameter greater than $5.5 \mathrm{~cm}$. Patients with BAV had a diameter greater than $4.5 \mathrm{~cm}$, and $36.6 \%$ of patients with a tricuspid aortic valve had a diameter greater than $5.5 \mathrm{~cm}$. In the AAAD group, the mean diameter of the ascending aorta was $4.9 \pm 0.8 \mathrm{~cm}$. The maximum diameter found was $7.6 \mathrm{~cm}$.
A diameter greater than $5.5 \mathrm{~cm}$ was observed in $18 \%$ of patients. In the only case of BAV, the diameter was $5.8 \mathrm{~cm}$.

As expected, the differences in the diameter of the ascending aorta were shown to be statistically significant when comparing the AAAD and aneurysms groups to the control group (Figure 4). In particular, compared to patients without aortic pathologies, this difference was $1.6 \mathrm{~cm}$ in the case of aneurysm and $1.4 \mathrm{~cm}$ in the case of AAAD. Differences in aortic root diameter (Figure 4) were also significant with larger diameters in patients with ascending aortic aneurysm or AAAD compared to the control group $(\mathrm{P}<0.001)$ (Table 3). In particular, 5 patients with aortic AAAD (7\%) and $4(5.1 \%)$ patients with ascending aortic 


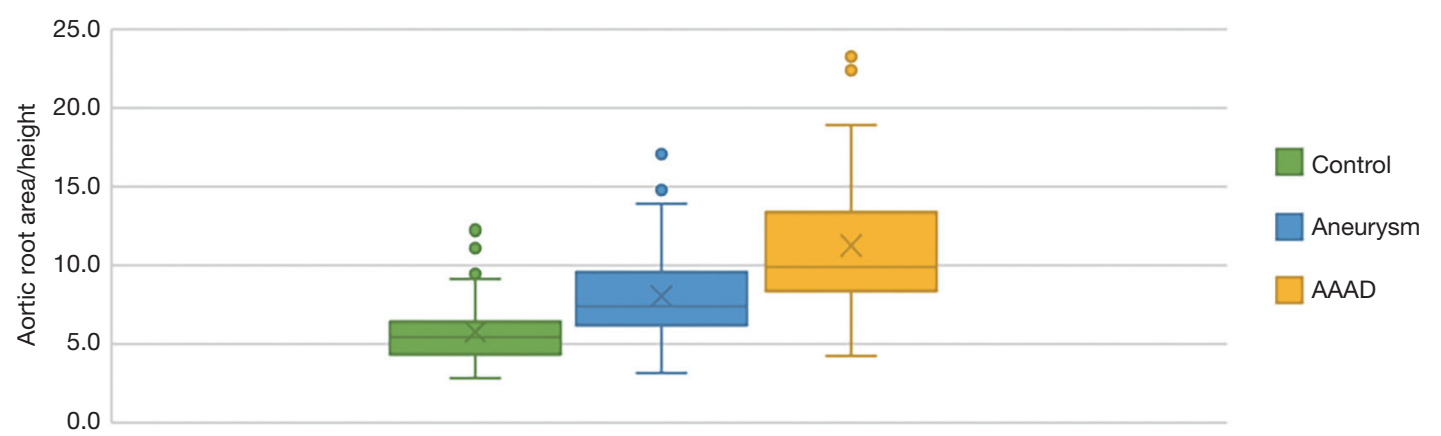

Figure 5 Box-and-whiskers plots presenting aortic root area/height in the AAAD, Aneurysm and control groups. AAAD, acute type A aortic dissection.

aneurysm had an aortic root diameter $>5.5 \mathrm{~cm}$. The mean diameter of the descending aorta was comparable in the AAAD and "aneurysms" groups $(3.0 \mathrm{~cm})$ and slightly smaller in the control group $(2.5 \mathrm{~cm})(\mathrm{P}=0.1)$ (Figure 4).

\section{Aortic root area/beight}

Multiple comparisons of aortic root area/height among the three groups (Figure 5) showed significant differences between patients with aneurysm and AAAD compared to the control group $(\mathrm{P}<0.001)$ and between patients with aneurysm compared to AAAD $(\mathrm{P}<0.001)$. The mean Svensson index in the control group was $5.7 \pm 1.0 \mathrm{~cm}^{2} / \mathrm{m}$, $8.0 \pm 2.7 \mathrm{~cm}^{2} / \mathrm{m}$ in the aneurysm patients and $11.23 \pm 3.9 \mathrm{~cm}^{2} / \mathrm{m}$ in the AAAD group (Table 3).

\section{Ascending aorta length}

In the frontal plane, the length of the ascending aorta was significantly greater in patients affected by aortic pathology (AAAD and aneurysm) than in the control group $(\mathrm{P}<0.005$ in both comparisons) (Figure 6A). In particular, compared to healthy aortas, this difference amounted to $2.1 \mathrm{~cm}$ in the aortas in case of AAAD and $1.8 \mathrm{~cm}$ in those affected by aneurysm.

This difference was also significant in the sagittal plane $(\mathrm{P}<0.005)$ (Figure $6 A)$ with $2.1 \mathrm{~cm}$ longer aortas in the AAAD group and $2.0 \mathrm{~cm}$ in the aneurysm group compared to the control group.

No significant differences were found when comparing the length of the ascending aorta, in both planes, of patients with aortic aneurysm and $\mathrm{AAAD}(\mathrm{P}=0.4$ in the frontal plane and $\mathrm{P}=1$ in the sagittal plane). Aortas affected by dissection or aneurysm, when compared to the healthy aortas, showed statistically significant differences in aortic lengths in both planes indexed to the patient's height and BSA (Figure 6B,C).

\section{Ascending aorta volume}

Multiple comparisons showed a significant difference between the AAAD and aneurysm groups compared to the control group of $60 \mathrm{~cm}^{3}$ ( $\mathrm{P}<0.001$ in both comparisons) (Figure $7 A$ ). Conversely, no significant differences were documented comparing AAAD patients to the aortic aneurysm group (Figure 7A). The differences were also confirmed to be significant for the aortic volume values indexed to the BSA with a mean difference, compared to the control group, of $31.5 \mathrm{~cm}^{3} / \mathrm{m}^{2}$ in the AAAD group and of $34.6 \mathrm{~cm}^{3} / \mathrm{m}^{2}$ in the aneurysm group (Figure $7 B$ ).

\section{Discussion}

In the absence of connective tissue disorder, international guidelines $(7,8)$ recommend prophylactic replacement of the ascending aorta for diameters greater than $55 \mathrm{~mm}$, a cut-off considered to be the most important morphological risk factor for AAAD. In case of bicuspid aortic valve or in presence of elastopathy, the threshold recommended by international guidelines is $\geq 45-50 \mathrm{~mm}(7,8)$.

Despite several improvements concerning primary and secondary prevention, pharmacological therapy and diagnostic prevention strategies, the annual incidence rates of aortic dissection remained stable over the past decades, ranging from 2.9 to 4.4 per 100,000 per year (10-12). Reported incidence reached 6/100,000/year (13) and 12.46/100,000/year (14).

According to an International Registry of Acute Aortic Dissections (IRAD) study, nearly $60 \%$ of cases of AAAD 
A

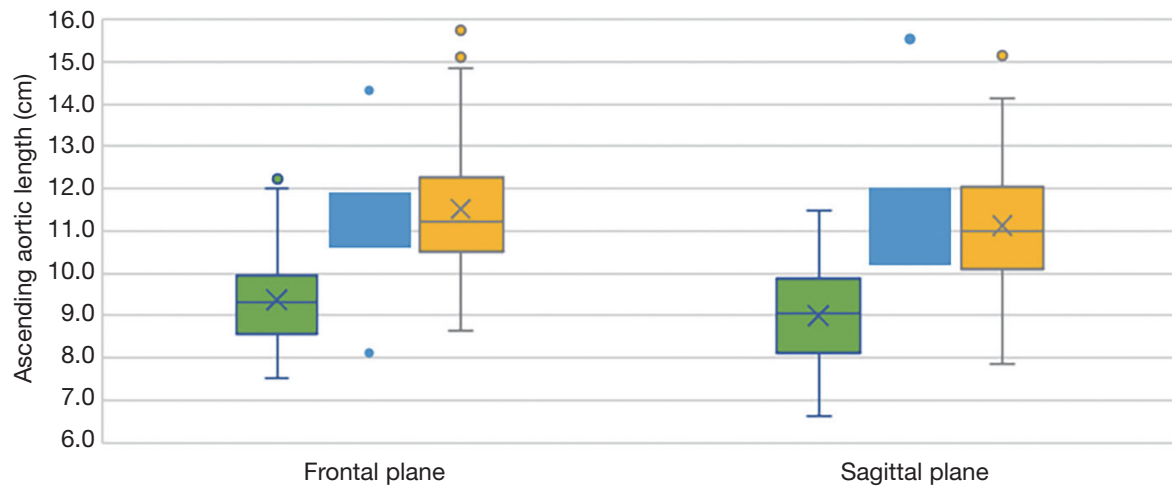

B

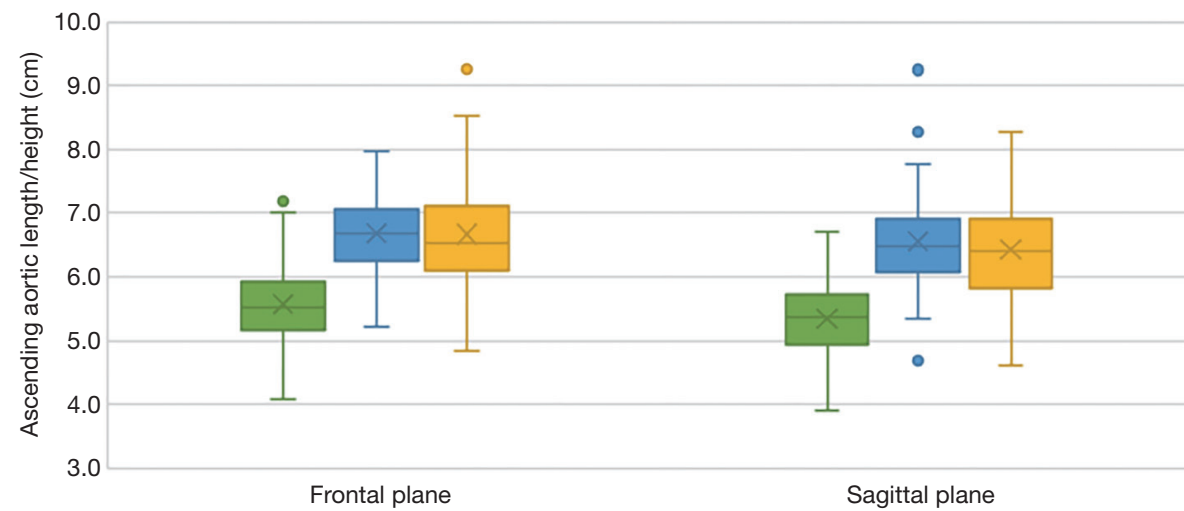

Control

Aneurysm

$\square$ AAAD

Control

Aneurysm

AAAD
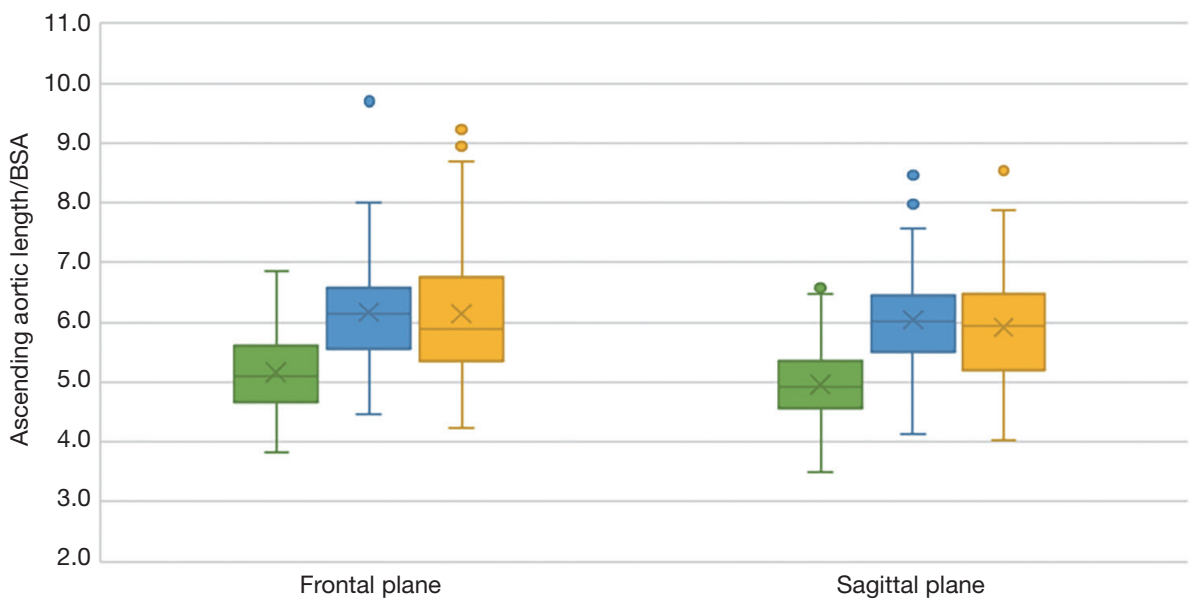

Control

Aneurysm

AAAD

Figure 6 Box-and-whiskers plots presenting ascending aortic length, in both frontal and sagittal planes, in the AAAD, aneurysm and control groups. (A) Ascending aortic length. (B) Ascending aortic length indexed by height. (C) Ascending aortic length indexed by BSA. AAAD, acute type A aortic dissection; BSA, body surface area.

had an ascending aortic diameter of less than $5.5 \mathrm{~cm}$ at the time of diagnosis (15), representing the so called "aortic size paradox" (15-17).

The threshold value of aorta's diameter, requiring preventive surgery, is largely based on the publications of Elefteriades (18,19), Davies (20) and Ergin (21) and guidelines have remained unchanged for a long time $(7,8)$. These studies were based on imaging data collected in the 1990s and early 21st century. At that time, measurements of aorta were performed mainly on axial images and therefore only two-dimensional (2D) images and measurements. In comparison, in the last 10 years, technological advances 

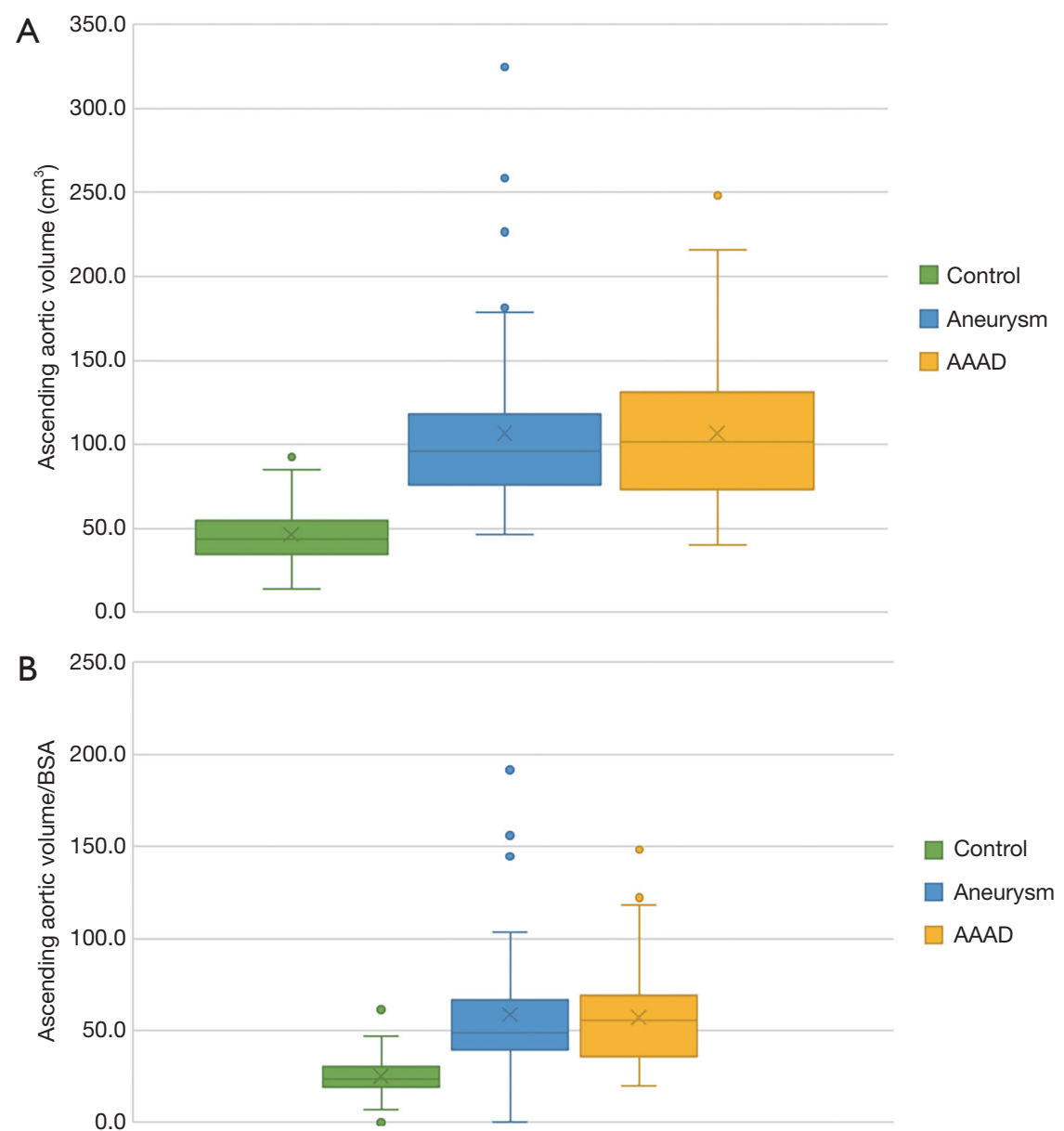

Figure 7 Box-and-whiskers plots presenting ascending aortic volume in the AAAD, aneurysm and control groups. (A) Ascending aortic volume. (B) Ascending aortic volume indexed by BSA. AAAD, acute type A aortic dissection; BSA, body surface area.

have allowed the acquisition of multilayered and highresolution CT and MRI images as well as the possibility of obtaining detailed three-dimensional (3D) reconstructions of the human arterial system.

Another issue to be considered is the changes of the aortic diameter when dissection occurs. The aortic circumference increases significantly due to the aortic dissection itself and the cases, studied retrospectively, could involve aortas with smaller diameters than in natural history analysis $(17,22,23)$.

Our results showed that the mean diameter of the ascending aorta, measured in patients with AAAD was $4.9 \pm 0.8 \mathrm{~cm}$ with only 18 of 71 patients $(25.3 \%)$ having a diameter greater than the cut-off value. Beside these results, if adjusted to pre-dissection diameters as described by Rylski et al. (17), none of 71 patients would have presented an ascending aortic diameter that exceeded the cut-off defined by international guidelines. Our results are similar to the data of the International Registry of Acute Aortic Dissection (IRAD) (15) and from other observational studies $(16,17)$.

Since AAAD occurs by diameters lower than this threshold value, we could conclude that the maximum transverse diameter is not an optimal value to detect aortas at risk of dissection. Therefore, it becomes of primary importance the identification of other morphological parameters able to expand and make more accurate stratification of acute aortic dissection risk.

In 2010, the use of the ratio of maximal ascending aorta/aortic root area divided by the patient's height was introduced in the international guidelines (8). More particularly, a cut-off of aortic area/height $>10 \mathrm{~cm}^{2} / \mathrm{m}$ has been shown to be associated with AAAD in patients with Marfan syndrome and bicuspid aortic valve $(24,25)$. 
However, there is a lack of large-scale data evaluating the prognostic utility of this index in the context of aortic root or ascending aortic aneurysms in patients with tricuspid aortic valve. In our results, multiple comparisons of the Svensson index showed significant differences in patients affected by ascending aorta aneurysm and AAAD compared to healthy aortas. This significance was also confirmed by comparing aneurysmal aortas with AAAD.

To better understand the pathogenesis of aortic dissection, the aortic wall composition, stress and compliance must be considered.

Given that rupture is a multifaceted biological process involving biochemical, cellular, and proteolytic influences, in addition to biomechanics factors it would be of paramount importance to identify novel targets to monitor growth rate and treat aneurysms before they rupture. Moreover, although it was previously believed that aneurysms simply represented a form of atherosclerosis, aortic aneurysmal disease is now recognized as a multifaceted distinct degenerative process involving all layers of the vessel wall. It is well known that the pathophysiology of aortic aneurysms is marked by several events boosting each other: the vessel inflammation, the infiltration of the aortic wall by lymphocytes and macrophages; the progressive destruction of elastin and collagen in the media and adventitia by proteases, including matrix metalloproteinases; the loss of smooth-muscle cells with weakening of the media; the derangement of the notch pathway (26-33).

Vascular smooth muscle cells, loss and fragmentation of elastin fibers and/or Mucoid Extracellular Matrix Accumulation (cystic medial necrosis and medionecrosis) are the main abnormalities of the ascending aorta wall described in case of bicuspid aortic valve and Genetic diseases (Marfan syndrome, Ehlers-Danlos syndrome Type IV A, Loeys-Dietz syndrome) (34).

On the other side, from the literature, it appears that the circumferential component of the wall stress and its stiffness are the main determinants in the pathogenesis of type aortic dissection. However, the axial component of the wall stress and the resulting longitudinal dilation or elongation of the ascending aorta have been ignored in the pathogenetic and pathophysiological models of aortic dissection. In fact, according to a recent study that examined a healthy aorta compliance in an ex vivo porcine model (35), it has been shown that at the level of the ascending aorta, longitudinal compliance is distributed asymmetrically (greater at the level of the external curvature than the internal one) and that the longitudinal compliance exceeds the circumferential one (2). The study also highlighted, that the tensile strength of the aortic tissue in the longitudinal direction is less than the circumferential direction (2). These, along with other results in the literature (36-41), may explain the most frequently observed horizontal direction of an AAAD entry (intimal tear) (42).

In our analysis, the aortas in the case of AAAD and aneurysm, in the frontal and sagittal planes, were significantly longer when compared with the control group. The differences are confirmed also by indexing the length to the patient's height and BSA. Heuts et al. (43) reported that, after retrospective correction in order to obtain the "predicted" dimensions as reported by Rylski et al. (17), the ascending aorta was longer and dilated in patients with AAAD than in healthy controls $(78.6 \pm 8.8$ vs. $68.9 \pm 7.2 \mathrm{~mm}$, $\mathrm{P}<0.001,34.4 \pm 3.2$ vs. $39.4 \pm 5.7 \mathrm{~mm}, \mathrm{P}<0.001$, respectively).

In addition, the length and diameter of the ascending aorta were independent predictors for aortic dissection (Or=5.3, $\mathrm{P}<0.001$ and $\mathrm{Or}=8.6, \mathrm{P}=0.001$, respectively) (43).

In a risk stratification, ascending aorta length values, ranging between 11.5 and $12.0 \mathrm{~cm}$ and between 12.5 and $13.0 \mathrm{~cm}$, were associated with a large increase in the possibility of adverse aortic acute events (6). An ascending aorta length $\geq 13 \mathrm{~cm}$ was associated with an average annual rate of adverse aortic events nearly 5 times higher than a size $<9 \mathrm{~cm}$ and 32 times higher than a size $<7 \mathrm{~cm} \mathrm{(6).}$

The ascending aorta length showed a moderate, even imperfect, correlation with the height and BSA of the patients. Ascending aorta length had been strongly correlated with age (2). The lack of correlation in our results could be basically linked to three factors: (I) the small number of the control group; (II) the asymmetric age distribution in the control group $(85 \%$ of patients were over 60 years); and (III) the control group patients were patients affected by heart disease and $45.3 \%$ of them were diagnosed with severe aortic stenosis. The last factor, although it contributes in part to the failure correlation of aortic parameters with age, only confirms our hypothesis since an aortic elongation of the aorta has been described in pathological conditions such as aortic stenosis (44).

These results allow us to hypothesize and speculate that aortic elongation may be another risk factor for the development of AAAD. The pronounced aortic elongation in aneurysmal aortas compared to healthy aortas supports this hypothesis. Our results, in accordance with the results of Krüger (2,3,5), Lescan (4), Heuts (43), Wu (6) et al. showed that the length of the ascending aorta could represent another milestone for the recommendation of 
elective and preventive replacement of the ascending aorta.

The monitoring of aneurysmal evolution on the basis of diameters presents a high risk of inter-observer variability since measurements are often carried out at different levels or angles. Furthermore, the measurements of the maximum diameter have an additional disadvantage: it does not describe the aortic growth that constitutes a threedimensional process. The elongation and deformation of the cylindrical structure of the ascending aorta are two scenarios of positive remodeling that are not necessarily be associated with an increase in transverse diameters $(45,46)$.

In this regard, we performed the measurement of the volumes of the ascending aorta since these are a function of the diameter and length of the aorta. A measurement that, as mentioned by literature, increases the reliability of monitoring of aortic morphological changes with computed tomography scans (47).

The aortic volume showed a moderate correlation with age in the control group. Multiple comparisons of aortic volumes as absolute and indexed values for the BSA, showed significantly higher values in the case of ascending aortic aneurysm and AAAD compared to the control group. A possible criticism of the use of volume to track the growth of an aneurysm is that the diameter may be a better predictor of the risk of rupture than the volume; given the dependence of wall tension on diameter and since a long thin aorta may be less at risk than a short aorta of the same volume. However, the measurement of the aortic volume showed excellent reproducibility in the followup of ascending thoracic aortic aneurysms (48). For this purpose, the measurement of the aortic area and volume could represent a tool of paramount importance for the description of the three-dimensional phenomenon of aortic growth and aneurysmatic evolution.

\section{Conclusions}

In the present study, we demonstrated that aortic diameter, considered separately, is not an optimal predictor of aortic dissection. We have also shown that, in the case of an aortic aneurysm or dissection, the ratio of maximal ascending aorta/aortic root area divided by the patient's height, aortic length and volume are increased compared to healthy aortas. A limitation of our study is represented by the fact that our dataset is not adequate to identify independent risk factors for AAAD or to quantify the risk. However, in our opinion, the introduction into clinical practice of measurements of the area, length and volume of the aorta, as absolute or indexed values, could improve the selection of patients who would benefit from preventive aortic replacement. We believe that developing algorithmbased risk scores that contemplate all these variables would allow for prompt identification of patients at risk. In addition, recently introduced techniques in clinical practice, such as four-dimensional flow MRI (4D) and positron emission tomography (PET) (49), that allow the analysis of hemodynamic and inflammatory processes underlying the progression of an aneurysm, in addition to genetic and molecular investigations $(32,33)$, could further improve the prevention of acute aortic dissections.

\section{Limitations}

This study has two main limitations:

(I) The retrospective nature of the study makes it unsuitable for identifying risk factors. A prospective study, however, would be particularly complicated, given the need for a long and indefinite followup time for subjects ascertained to be at risk and is ethically problematic due to the inevitable exposure of the subjects to radiation and iodinated contrast media. In our opinion, the design of this study, like others in the literature, represents an equally valid alternative method.

(II) CT studies, dating back to 15 years, have been included. Therefore, not all studies were of optimal quality, although adequate. Also, motion artifacts, particularly in the aortic root, can impede accurate measurement. Mostly of the CT exams were performed in peripheral centers and patients were subsequently transferred to our center to undergo emergency surgery. These problems may be solved using ECG-gated techniques and latest generation scanners.

\section{Acknowledgments}

Funding: None.

\section{Footnote}

Reporting Checklist: The authors have completed the STROBE reporting checklist. Available at http://dx.doi. org/10.21037/jtd-21-119

Data Sharing Statement: Available at http://dx.doi. 
org/10.21037/jtd-21-119

Peer Review File: Available at http://dx.doi.org/10.21037/jtd21-119

Conflicts of Interest: All authors have completed the ICMJE uniform disclosure form (available at http://dx.doi. org/10.21037/jtd-21-119). The authors have no conflicts of interest to declare.

Ethical Statement: The authors are accountable for all aspects of the work in ensuring that questions related to the accuracy or integrity of any part of the work are appropriately investigated and resolved. The study was conducted in accordance with the Declaration of Helsinki (as revised in 2013). The National Code on Clinical Trials has declared that ethics approval is not necessary for real retrospective studies. All our patients sign a consent for medical/surgical treatment, privacy terms, future studies and participate in research.

Open Access Statement: This is an Open Access article distributed in accordance with the Creative Commons Attribution-NonCommercial-NoDerivs 4.0 International License (CC BY-NC-ND 4.0), which permits the noncommercial replication and distribution of the article with the strict proviso that no changes or edits are made and the original work is properly cited (including links to both the formal publication through the relevant DOI and the license). See: https://creativecommons.org/licenses/by-nc-nd/4.0/.

\section{References}

1. Miscusi M. BioGlue and spine surgery. Spine $\mathrm{J}$ 2011;11:983; author reply 983-4.

2. Krüger T, Forkavets $\mathrm{O}$, Veseli $\mathrm{K}$, et al. Ascending aortic elongation and the risk of dissection. Eur J Cardiothorac Surg 2016;50:241-7.

3. Krüger T, Oikonomou A, Schibilsky D, et al. Aortic elongation and the risk for dissection: the Tubingen Aortic Pathoanatomy (TAIPAN) projectdagger. Eur J Cardiothorac Surg 2017;51:1119-26.

4. Lescan M, Veseli K, Oikonomou A, et al. Aortic Elongation and Stanford B Dissection: The Tubingen Aortic Pathoanatomy (TAIPAN) Project. Eur J Vasc Endovasc Surg 2017;54:164-9.

5. Krüger T, Sandoval Boburg R, Lescan M, et al. Aortic elongation in aortic aneurysm and dissection: the
Tubingen Aortic Pathoanatomy (TAIPAN) project. Eur J Cardiothorac Surg 2018;54:26-33.

6. Wu J, Zafar MA, Li Y, et al. Ascending Aortic Length and Risk of Aortic Adverse Events: The Neglected Dimension. J Am Coll Cardiol 2019;74:1883-94.

7. Erbel R, Aboyans V, Boileau C, et al. 2014 ESC Guidelines on the diagnosis and treatment of aortic diseases. Kardiol Pol 2014;72:1169-252.

8. Hiratzka LF, Bakris GL, Beckman JA, et al. 2010 ACCF/AHA/AATS/ACR/ASA/SCA/SCAI/SIR/STS/ SVM guidelines for the diagnosis and management of patients with Thoracic Aortic Disease: a report of the American College of Cardiology Foundation/American Heart Association Task Force on Practice Guidelines, American Association for Thoracic Surgery, American College of Radiology, American Stroke Association, Society of Cardiovascular Anesthesiologists, Society for Cardiovascular Angiography and Interventions, Society of Interventional Radiology, Society of Thoracic Surgeons, and Society for Vascular Medicine. Circulation 2010;121:e266-369.

9. Flachskampf FA. How Exactly Do You Measure That Aorta?: Lessons From Multimodality Imaging. JACC Cardiovasc Imaging 2016;9:227-9.

10. Mészáros I, Morocz J, Szlavi J, et al. Epidemiology and clinicopathology of aortic dissection. Chest 2000;117:1271-8.

11. Clouse WD, Hallett JW Jr, Schaff HV, et al. Acute aortic dissection: population-based incidence compared with degenerative aortic aneurysm rupture. Mayo Clin Proc 2004;79:176-80.

12. DeMartino RR, Sen I, Huang Y, et al. PopulationBased Assessment of the Incidence of Aortic Dissection, Intramural Hematoma, and Penetrating Ulcer, and Its Associated Mortality From 1995 to 2015. Circ Cardiovasc Qual Outcomes 2018;11:e04689.

13. Howard DP, Banerjee A, Fairhead JF, et al. Populationbased study of incidence and outcome of acute aortic dissection and premorbid risk factor control: 10-year results from the Oxford Vascular Study. Circulation 2013;127:2031-7.

14. Wundram M, Falk V, Eulert-Grehn JJ, et al. Incidence of acute type A aortic dissection in emergency departments. Sci Rep 2020;10:7434.

15. Pape LA, Tsai TT, Isselbacher EM, et al. Aortic diameter $>\mathrm{or}=5.5 \mathrm{~cm}$ is not a good predictor of type A aortic dissection: observations from the International Registry of Acute Aortic Dissection (IRAD). Circulation 
2007;116:1120-7.

16. Parish LM, Gorman JH, 3rd, Kahn S, et al. Aortic size in acute type A dissection: implications for preventive ascending aortic replacement. Eur J Cardiothorac Surg 2009;35:941-5; discussion 5-6.

17. Rylski B, Blanke P, Beyersdorf F, et al. How does the ascending aorta geometry change when it dissects? J Am Coll Cardiol 2014;63:1311-9.

18. Coady MA, Rizzo JA, Hammond GL, et al. What is the appropriate size criterion for resection of thoracic aortic aneurysms? J Thorac Cardiovasc Surg 1997;113:476-91; discussion 489-91.

19. Elefteriades JA. Natural history of thoracic aortic aneurysms: indications for surgery, and surgical versus nonsurgical risks. Ann Thorac Surg 2002;74:S1877-80; discussion S92-8.

20. Davies RR, Goldstein LJ, Coady MA, et al. Yearly rupture or dissection rates for thoracic aortic aneurysms: simple prediction based on size. Ann Thorac Surg 2002;73:17-27; discussion 27-8.

21. Ergin MA, Spielvogel D, Apaydin A, et al. Surgical treatment of the dilated ascending aorta: when and how? Ann Thorac Surg 1999;67:1834-9; discussion 1853-6.

22. Mansour AM, Peterss S, Zafar MA, et al. Prevention of Aortic Dissection Suggests a Diameter Shift to a Lower Aortic Size Threshold for Intervention. Cardiology 2018;139:139-46.

23. Okuno T, Yamaguchi M, Okada T, et al. Endovascular creation of aortic dissection in a swine model with technical considerations. J Vasc Surg 2012;55:1410-8.

24. Svensson LG, Khitin L. Aortic cross-sectional area/ height ratio timing of aortic surgery in asymptomatic patients with Marfan syndrome. J Thorac Cardiovasc Surg 2002;123:360-1.

25. Svensson LG, Kim KH, Lytle BW, et al. Relationship of aortic cross-sectional area to height ratio and the risk of aortic dissection in patients with bicuspid aortic valves. J Thorac Cardiovasc Surg 2003;126:892-3.

26. He R, Guo DC, Sun W, et al. Characterization of the inflammatory cells in ascending thoracic aortic aneurysms in patients with Marfan syndrome, familial thoracic aortic aneurysms, and sporadic aneurysms. J Thorac Cardiovasc Surg 2008;136:922-9, 929.e1.

27. Manning BD, Cantley LC. AKT/PKB signaling: navigating downstream. Cell 2007;129:1261-74.

28. Barbour JR, Spinale FG, Ikonomidis JS. Proteinase systems and thoracic aortic aneurysm progression. J Surg Res 2007;139:292-307.
29. Nagasawa A, Yoshimura K, Suzuki R, et al. Important role of the angiotensin II pathway in producing matrix metalloproteinase-9 in human thoracic aortic aneurysms. J Surg Res 2013;183:472-7.

30. Rabkin SW. Differential expression of MMP-2, MMP9 and TIMP proteins in thoracic aortic aneurysm comparison with and without bicuspid aortic valve: a metaanalysis. Vasa 2014;43:433-42.

31. Zou S, Ren P, Nguyen M, et al. Notch signaling in descending thoracic aortic aneurysm and dissection. PLoS One 2012;7:e52833.

32. Balistreri CR, Crapanzano F, Schirone L, et al. Deregulation of Notch1 pathway and circulating endothelial progenitor cell (EPC) number in patients with bicuspid aortic valve with and without ascending aorta aneurysm. Sci Rep 2018;8:13834.

33. Balistreri CR, Forte M, Greco E, et al. An overview of the molecular mechanisms underlying development and progression of bicuspid aortic valve disease. J Mol Cell Cardiol 2019;132:146-53.

34. Halushka MK, Angelini A, Bartoloni G, et al. Consensus statement on surgical pathology of the aorta from the Society for Cardiovascular Pathology and the Association For European Cardiovascular Pathology: II. Noninflammatory degenerative diseases - nomenclature and diagnostic criteria. Cardiovasc Pathol 2016;25:247-57.

35. Krüger T, Veseli K, Lausberg H, et al. Regional and directional compliance of the healthy aorta: an ex vivo study in a porcine model. Interact Cardiovasc Thorac Surg 2016;23:104-11.

36. Kassab GS. Biomechanics of the cardiovascular system: the aorta as an illustratory example. J R Soc Interface 2006;3:719-40.

37. Tonar Z, Kubikova T, Prior C, et al. Segmental and age differences in the elastin network, collagen, and smooth muscle phenotype in the tunica media of the porcine aorta. Ann Anat 2015;201:79-90.

38. Choudhury N, Bouchot O, Rouleau L, et al. Local mechanical and structural properties of healthy and diseased human ascending aorta tissue. Cardiovasc Pathol 2009;18:83-91.

39. Martin C, Pham T, Sun W. Significant differences in the material properties between aged human and porcine aortic tissues. Eur J Cardiothorac Surg 2011;40:28-34.

40. Krüger T, Grigoraviciute A, Veseli K, et al. Elastic properties of the young aorta: ex vivo perfusion experiments in a porcine model. Eur J Cardiothorac Surg 
2015;48:221-7.

41. Guo X, Kassab GS. Variation of mechanical properties along the length of the aorta in $\mathrm{C} 57 \mathrm{bl} / 6$ mice. Am J Physiol Heart Circ Physiol 2003;285:H2614-22.

42. Hirst AE Jr, Johns VJ Jr, Kime SW Jr. Dissecting aneurysm of the aorta: a review of 505 cases. Medicine (Baltimore) 1958;37:217-79.

43. Heuts S, Adriaans BP, Gerretsen S, et al. Aortic elongation part II: the risk of acute type A aortic dissection. Heart 2018;104:1778-82.

44. Toba T, Mori S, Izawa Y, et al. Ascending aortic elongation and correlative change in overall configuration of the proximal aorta in elderly patients with severe aortic stenosis. Clin Anat 2020;33:1240-8.

45. Martufi G, Auer M, Roy J, et al. Multidimensional growth measurements of abdominal aortic aneurysms. J Vasc Surg 2013;58:748-55.

Cite this article as: Saade $W$, Vinciguerra $M$, Romiti S, Macrina F, Frati G, Miraldi F, Greco E. 3D morphometric analysis of ascending aorta as an adjunctive tool to predict type A acute aortic dissection. J Thorac Dis 2021;13(6):3443-3457. doi: 10.21037/jtd-21-119
46. Lindquist Liljeqvist M, Hultgren R, Gasser TC, et al. Volume growth of abdominal aortic aneurysms correlates with baseline volume and increasing finite element analysis-derived rupture risk. J Vasc Surg 2016;63:14341442.e3.

47. Geisbüsch S, Stefanovic A, Schray D, et al. A prospective study of growth and rupture risk of small-to-moderate size ascending aortic aneurysms. J Thorac Cardiovasc Surg 2014;147:68-74.

48. Heuts S, Adriaans BP, Rylski B, et al. Evaluating the diagnostic accuracy of maximal aortic diameter, length and volume for prediction of aortic dissection. Heart 2020;106:892-7.

49. Adriaans BP, Wildberger JE, Westenberg JJM, et al. Predictive imaging for thoracic aortic dissection and rupture: moving beyond diameters. Eur Radiol 2019;29:6396-404. 